\title{
KARTAGENER'S SYNDROME: A RARE CASE REPORT
}

\author{
B. S. Satish Prasad ${ }^{1}$
}

\section{HOW TO CITE THIS ARTICLE:}

B. S. Satish Prasad. "Kartagener's Syndrome: A Rare Case Report". Journal of Evolution of Medical and Dental Sciences 2015; Vol. 4, Issue 01, January 01; Page: 112-115, DOI: 10.14260/jemds/2015/16

ABSTRACT: Kartagener syndrome is a subset of primary ciliary dyskinesia, an autosomal recessive condition characterized by abnormal ciliary structure or function leading to impaired mucociliary clearance. The findings of CT thorax, abdomen and PNS support the clinical diagnosis of the Kartageners Syndrome. We report the CT findings of this rare syndrome.

INTRODUCTION: Kartagener's syndrome is a rare disorder which is seen in nearly half of the cases of primary ciliary dyskinesia. Primary ciliary dyskinesia is an inherited autosomal recessive condition characterized by bronchiectasis, sinusitis and otitis media. When situs inversus is associated with primary ciliary dyskinesia then it is referred to as Kartagener's syndrome.(1) The prevalence of Kartageners syndrome is 1 in 32000 live births.(2) No gender predilection is recognized.(3)

CASE REPORT: A 24 year old male patient presented with complaints of productive cough, rhinorrhea and headache since childhood with episodic fever and worsening of symptoms presented for Contrast enhanced CT which revealed the following;

Fig. 1 \& 2: Axial CT lung window showing cystic dilatation of bronchi with thickened wall suggestive of bronchiectasis distributed predominantly in bilateral upper lobes and right middle \& lower lobes.

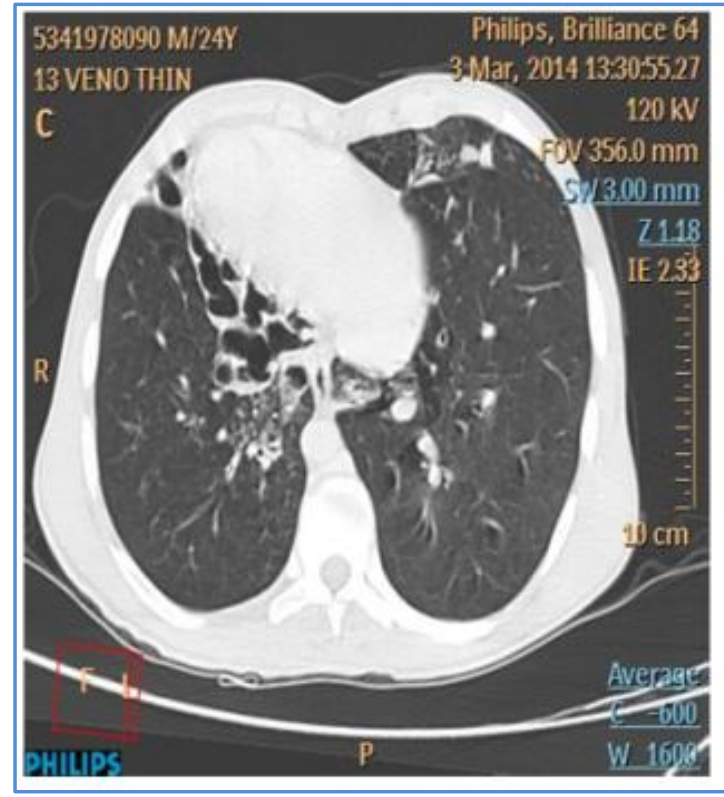

Fig. 1

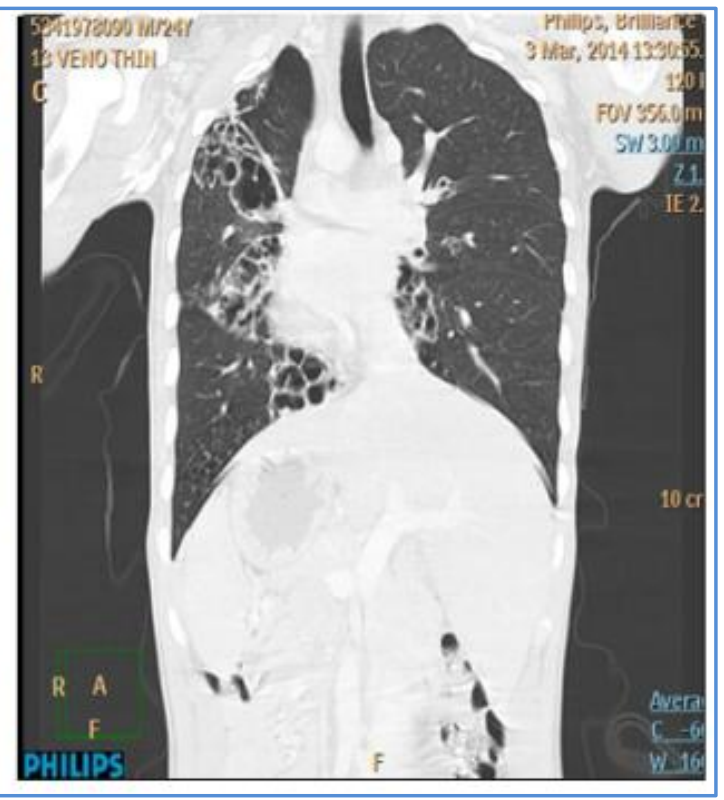

Fig. 2 


\section{CASE REPORT}

Fig. 3: Abdominal CT sagittal section showing dextrocardia with liver on the left side and the spleen on right side suggestive of situs inversus totalis.

Fig. 4: Coronal CT of Paranasal sinuses shows bilateral maxillary sinusitis bilateral middle and inferior turbinates showing polypoid changes.

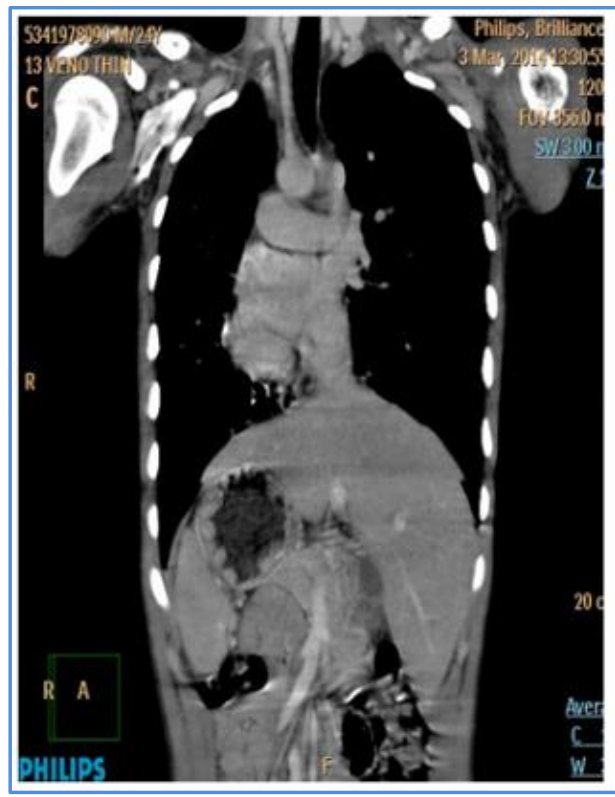

Fig. 3

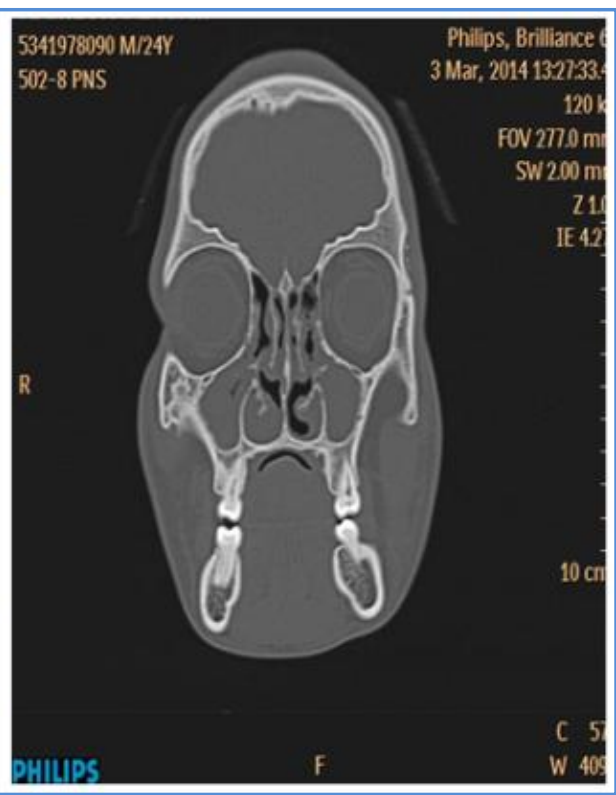

Fig. 4

DISCUSSION: Kartagener's syndrome is characterised by the clinical trial of situs inversus, chronic sinusitis and/or nasal polyposis and bronchiectasis. These features are attributed to abnormal ciliary motility.

Most important clinical manifestations include chronic upper and lower respiratory tract disease resulting from ineffective mucociliary clearance; the symptoms of chronic sinusitis, bronchitis, and bronchiectasis are more severe during the first decade of life but remit somewhat by the end of adolescence. Males are generally infertile because of immotile sperms, however some males have completely normal spermatozoa and cases of semi-sterility in females have been reported. Patients with Kartagener's syndrome may also have anosmia.

Chest radiographs may illustrate bronchial wall thickening as an early manifestation of chronic infection, hyperinflation, atelectasis, bronchiectasis, and situs inversus that strongly suggests Kartagener's syndrome (KS).

CT is substantially more sensitive than chest radiography for showing bronchiectasis, which is characterized by lack of bronchial tapering, bronchi visible in the peripheral $1 \mathrm{~cm}$ of the lungs, and an increased broncho-arterial ratio producing the so-called signet-ring sign. According to appearance and severity, bronchiectasis can be classified as cylindric, varicose, or cystic.(4) CT changes are milder than in cystic fibrosis. ${ }^{(5)}$ 


\section{DIFFERENTIAL DIAGNOSIS:}

1. Malignancy.

2. Interstitial lung diseases: idiopathic pulmonary fibrosis and idiopathic interstitial pneumonia.

3. Conditions associated with bronchiectasis:

i. Acquired (foreign body aspiration, tumor, lymphadenopathy, chronic obstructive pulmonary disease, and mucoid impaction).

ii. Congenital bronchial obstruction (Bronchomalacia, pulmonary sequestration yellow nail syndrome).

iii. Recurrent infection (Immunodeficiencies).

iv. Cystic fibrosis.

v. Alpha-1 antitrypsin deficiency.

CONCLUSION: CT scan of the chest, particularly high-resolution CT (HRCT) scanning, has gained importance in severity, grading and monitoring of Kartagener's syndrome for clinical management and intervention studies. Consideration should be given to this imaging technique early in the presentation of Kartagener syndrome, when a chest radiograph may not be sensitive enough to identify disease processes or when another differential is being considered.(6)

\section{REFERENCES:}

1. Vaibhav Shukla, Jalees Fatima, RituKaroli. An Unusual Presentation of Kartagener's Syndrome. JAPI. 2011. 59.

2. Bissonnette B, Luginbuehl I, Dalens BJ. Syndromes: Rapid recognition and perioperative implications, 2006.

3. Berdon WE, Willi U. Situsinversus, bronchiectasis, and sinusitis and its relation to immotile cilia: history of the diseases and their discoverers-Manes Kartagener and Bjorn Afzelius. Pediatr Radiol. 2004; 34 (1): 38-42.

4. Luce Cantin1, Alexander A. Bankier1 and Ronald L. Eisenberg.Bronchiectasis.American Journal of Roentgenology.2009; 193 (3): 158-171.

5. Noone PG, Leigh MW, Sannuti A et-al. Primary ciliary dyskinesia: diagnostic and phenotypic features. Am. J. Respir. Crit. Care Med. 2004; 169 (4): 459-67.

6. McManus I, Mitchison H, Chung E, Stubbings G, Martin N. Primary ciliarydyskinesia (Siewert's/Kartagener's syndrome): respiratory symptoms and psycho-social impact. BMC Pulm Med 2003; 3: 4. 


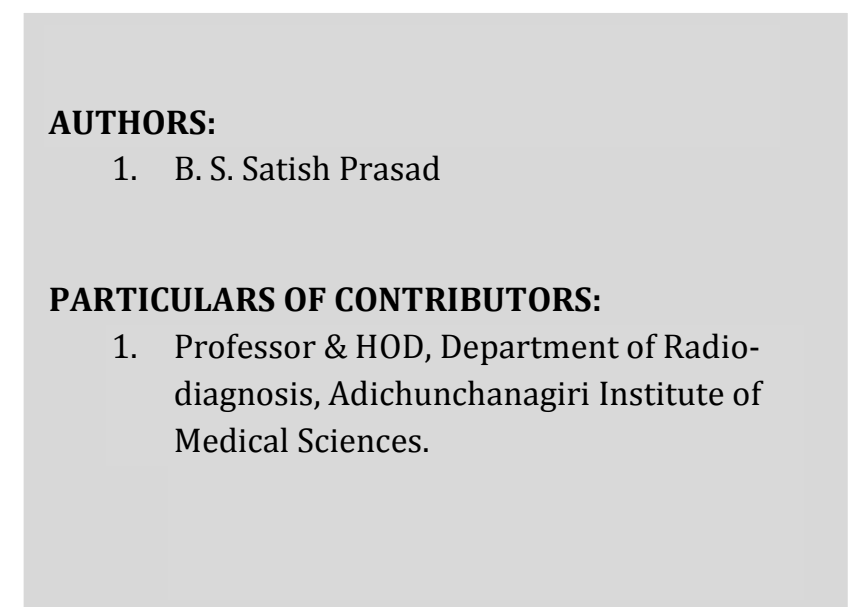

\author{
NAME ADDRESS EMAIL ID OF THE \\ CORRESPONDING AUTHOR: \\ Dr. B. S. Satish Prasad, \\ \# 214/Y, $3^{\text {rd }}$ Block, \\ $53^{\text {rd }}$ Cross, $13^{\text {th }}$ Main, \\ Rajaji Nagar, Bangalore-560010. \\ E-mail: satishprasad.bs@gmail.com
}

Date of Submission: 11/12/2014.

Date of Peer Review: 12/12/2014.

Date of Acceptance: 19/12/2014.

Date of Publishing: 01/01/2015. 